\title{
A special issue on the mathematics of subjective probability
}

\section{Gianluca Cassese ${ }^{1} \cdot$ Pietro Rigo $^{2} \cdot$ Barbara Vantaggi $^{3}$}

Published online: 3 June 2020

(c) Associazione per la Matematica Applicata alle Scienze Economiche e Sociali (AMASES) 2020

In Arrow's own words (Arrow 1951, p. 410), two different approaches are prevalent in dealing with risk-taking decisions. "The difference in (the two) viewpoints is related (...) to the dispute between those who interpret probability as a measure of degree of belief (...) and those who regard probability as a measure (objective) of relative frequency". Although most authors would likely agree with this broad distinction, there would probably be much less consensus of opinions on what do the authors included in the former group agree upon.

In introducing this special issue of Decision in Economics and Finance dedicated to the Mathematics of Subjective Probability, we do not intend to take stance on such general issues. Our view in this regard is quite simple: The subjective approach to probability consists in viewing probability as (part of) the solution to a given decision problem, rather than as a starting assumption. This idea is not far from the notion of coherence originally formulated by de Finetti (1937), but it can as well be seen as the starting point of many an approach in game theory, the theory of decisions, statistics, and other fields of interest. In fact several important developments in modern economics, such as the Choquet expected utility introduced by Schmeidler (1986), deduce a set function from a given set of axioms.

The challenge implicit in this approach is, of course, to obtain nice and tractable mathematical models even in the absence of a given initial probability. In choosing the papers to include in this issue, we required that they have a clear mathematical content. Berti et al. (2020) examine the problem of extending the notion of conditional

$\bowtie$ Gianluca Cassese

gianluca.cassese@unimib.it

Pietro Rigo

pietro.rigo@unibo.it

Barbara Vantaggi

barbara.vantaggi@uniroma1.it

1 Departimento di economia, metodi quantitative e strategie d'impresa, Università Milano-Bicocca, Milan, Italy

2 Departimento di scienze statistiche, Università di Bologna, Bologna, Italy

3 Dipartimento di metodi e modelli per l'economia, il territorio e la finanza, Università "La Sapienza", Rome, Italy 
probability, probably the most important achievement in classical probability, beyond the usual framework. This question has been considered in some classical works in subjective probability, such as Heath and Sudderth (1978) and Regazzini (1987). Lad and Sanfilippo (2020) study the match between predictive inferences and relative frequencies under exchangeability. Sudderth (2020), following the Dubins and Savage tradition, considers gambling problems with lim sup utility functions. Cassese (2020) focuses on the properties of semimodular set functions defined on a semilattice of sets and with values in an additive group. Eventually, Denti et al. (2020) examine the relationship between the rational inattention approach to decision problems and information theory.

We strongly believe that the subjective approach as we interpret it has many more contributions to offer and we wish to thank the participants to the MSP 2018 workshop for having shared some of them with us.

\section{References}

Arrow, K.J.: Alternative approaches to the theory of choice in risk-taking situations. Econometrica 19(4), 404-437 (1951)

Berti, P., Dreassi, E., Rigo, P.: A notion of conditional probability and some of its consequences. Decis. Econ. Finance this issue (2020)

Cassese, G.: Semilattices, canonical embeddings and representing measures. Decis. Econ. Finance this issue (2020)

de Finetti, B.: La prévision: Ses lois logiques, ses sources subjectives. Ann. Inst. Poincaré 7, 1-68 (1937)

Denti, T., Marinacci, M., Montrucchio, L.: A note on rational inattention and rate distortion theory. Decis. Econ. Finance this issue (2020)

Heath, D., Sudderth, W.D.: On finitely additive priors, coherence and extended admissibility. Ann. Stat. 6, 333-345 (1978)

Lad, F., Sanfilippo, G.: Predictive distributions that mimic frequencies over a restricted subdomain. Decis. Econ. Finance this issue (2020)

Regazzini, E.: Finetti's coherence and statistical inference. Ann. Stat. 15, 845-864 (1987)

Schmeidler, D.: Integral representation without additivity. Proc. Am. Math. Soc. 97(2), 255-261 (1986)

Sudderth, W.D.: Optimal markov strategies. Decis. Econ. Finance this issue (2020)

Publisher's Note Springer Nature remains neutral with regard to jurisdictional claims in published maps and institutional affiliations. 